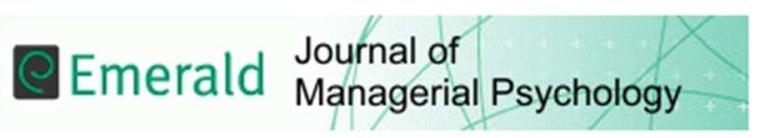

\title{
Swearing at Work: The Mixed Outcomes of Profanity
}

\begin{tabular}{|r|l|}
\hline Journal: & Journal of Managerial Psychology \\
\hline Manuscript ID & JMP-04-2016-0102.R2 \\
\hline Manuscript Type: & Research Paper \\
\hline Keywords: & $\begin{array}{l}\text { Cross-cultural management, Human resource management, qualitative } \\
\text { research }\end{array}$ \\
\hline \multicolumn{2}{|l}{} \\
\hline
\end{tabular}

\section{SCHOLARONE $^{\text {M }}$ \\ Manuscripts}




\title{
Swearing at Work: The Mixed Outcomes of Profanity
}

\begin{abstract}
Purpose: We explore the use and misuse of swearing in the workplace.

Design: Using a qualitative methodology, we interviewed 52 lawyers, medical doctors and business executives in the UK, France, and the U.S.

Findings: In contrast to much of the incivility and social norms literatures, we find that male and female business executives, lawyers and doctors of all ages admit to swearing. Further, swearing can lead to positive outcomes at the individual, interpersonal and group levels, including stressrelief, communication-enrichment, and socialization-enhancement.

Implications: An implication for future scholarship is that 'thinking out of the box' when exploring emotion related issues can lead to new insights. Practical implications include reconsidering and tolerating incivility under certain conditions.

Originality: We identified a case in which a negative phenomenon reveals counter-intuitive yet insightful results.
\end{abstract}

Keywords: workplace-misbehavior; incivility; profanity, swearing, counter-intuitive 
The workplace incivility literature (e.g. Pearson et al., 2000) has explored how uncivil behaviors at work may hinder professionalism and performance (e.g. Hadley, 2014; Priesemuth et al., 2013; Sears and Humiston, 2015; van Kleef, 2014), or even lead to bullying (Soylu and Sheehy-Skeffington, 2015), aggression (Hershcovis and Reich, 2013; Shao et al., 2011), and exclusion (Scott et al., 2014). While these findings make sense, the current literature discusses workplace misbehavior in a simplistic manner (Vardi and Weitz, 2004), mostly exploring negative outcomes.

Similarly, the emotional-labor literature (e.g. Brown et al., 2005; Gibson and Callister, 2010; Gray et al., 2011; Kennedy-Moore and Watson, 2001; Lindebaum and Fielden, 2011) indicates that positive emotions are acceptable at work (Lively, 2000), negative emotions should be suppressed (Kramer and Hess, 2002). A more intriguing approach would be to explore the potentially positive aspects of such behaviors. Indeed, early work regarding coping with work stress revealed that emotional release in the form of an immediate cathartic expression of feelings, such as losing temper, was quite effective (Dewe and Guest, 1990). More recently, a growing body of research has studied the potential asymmetrical effects of emotion-sharing in the workplace (e.g. Gibson and Callister, 2010; Gray et al., 2011; Kennedy-Moore and Watson, 2001; Lindebaum and Fielden, 2011). For example, Brown et al. (2005) conceptualized how stressful work events can lead to adverse emotional reactions as a coping response to regain emotional equanimity. However, more studies are required to explore how negative emotional displays by workers may not always be 'bad' (Hadley, 2014; Schilpzand et al., 2016). Given the evidence that negative behavior can lead to positive outcomes there is a need to explore whether negative emotional expression might produce positive outcomes.

We address these gaps in the research by focusing on the use of language in the workplace, particularly swearing, in three different contexts (U.S., UK and France). We focus on the highly educated segment of the population employed in reputable occupations - lawyers, medical doctors, business executives - that convey social norms incompatible with incivility (Andersen, 2009; Miller, 2000; Johnson and Lewis, 2010; Lim and Lee, 2011; Sliter et al., 2012). We 
explore the magnitude of the swearing phenomenon in the workplace to understand its meaning for individuals and explore its outcomes.

This research contributes to the professional/workplace (in)civility literature, the literature on social norms for professionals, and the literature on emotions at work by challenging the traditional view that social norms always preclude workplace incivility and that it is always negative. In addition, this research advances the field of workplace communication and the use, misuse and abuse of language in the workplace by showing how profanity is enacted and what its benefits might be. On a practical note, we offer business leaders insights into enabling communication and expression of emotion in a way that fits with contemporary language.

\section{Swearing as Workplace Incivility}

We ground our research within the professional/workplace (in)civility literature. Workplace incivility has been defined as low intensity antisocial behavior, or rude, insensitive or disrespectful behavior towards others (Pearson et al., 2001). Although incivility is mild in intensity, it can build up to more intense behaviors like violence (Johnson and Indvik, 2001). Work incivility can have dire consequences, such as decrease employee commitment, productivity, performance, job satisfaction and loyalty (Welbourne et al., 2016).

Swearing has rarely been investigated in the management literature, either psychologically or neurologically (see respectively Rassin and van der Heijden, 2005; Van Lancker and Cummings, 1999), although some work has been done on swearing as a social phenomenon (Baruch and Jenkins, 2007). Swearing is a form of workplace incivility because it violates the "respect" criterion of fairness in interpersonal treatment (Penney and Spector, 2005).

There is no common and acceptable definition for the term "swearing". Scholars use “offensive language," “cursing" and "dirty words" interchangeably (Kaye and Sapolsky, 2009). Swearing can also be the use of taboo words (Rassin and Muris, 2005). Swearing is also related to forms of verbal aggression such as loud noises, angry shouting, personal insults, cursing, foul language, and threats; although it does not always have an aggressive intent (Stone et al., 2010). 
Swearing can also be categorized (e.g. Montagu, 2001) into social swearing (occurring in interpersonal relationships with the purpose of creating or developing in-group solidarity) and annoyance swearing (mechanisms for relieving stress and tension in everyday life). Alternatively, cursing can include emotionally powerful offensive words (Jay, 2000) (e.g. the infamous Four-letter word $f^{* * *}$ or $s^{* * *}$ ), or emotionally harmful expressions understood as insults (e.g. kiss my ass, piss off, up yours).

\section{Causes of swearing}

The most prominent reason for swearing is to express negative emotions, particularly anger and frustration (Jay and Janschewitz, 2008). Swearing may also be a response to physical pain (Stephens and Umland, 2011). Other reasons for swearing include gaining attention, developing an interpersonal connection, showing familiarity, or increasing intimacy, belonging and informality (Young, 2004). In the workplace, swearing was observed as a way of reflecting solidarity and group cohesion (social aspects) and of releasing stress (psychological aspects) (Baruch and Jenkins, 2007) under challenging contemporary 'dark' careers (Baruch and Vardi, 2016). In addition, managers were found to deliberately express anger through swearing in order to influence subordinates (Lindebaum and Fielden, 2011).

Emotional-labor research discusses how frustrating events may lead to swearing because “emotions not only make us feel something, they make us feel like doing something" (Gross, 1999; p. 528). Evidence has indicated emotions create an 'action response' in an attempt to regulate and maintain states of emotional equilibrium (Hadley, 2014). The specific emotion regulation activities depend on individual factors such as emotional intelligence, personality, gender, and cultural context (Coupland et al., 2008). The logical target of emotional reactions at work are coworkers due to their physical and relational proximity, their shared experiences and knowledge, and their ability to provide both instrumental and emotional forms of support (Hadley, 2014). Although this emotion regulation through coworker interactions has benefits for 
the individual, it does not come without risk particularly because workplaces are governed by rules regarding the appropriateness of emotional expression (Diefendorff and Greguras, 2009).

\section{Swearing and the cultural context}

Swearing that might be a habitual part of an individual's language in a certain context may be misinterpreted as aggressive speech in another context (White, 2002). In addition, what qualifies as swearwords differ (Stone and Francis, 2010) because cultural values influence the semantics of offence in four domains: religion, taboo, disgust, and the laws (Jay, 2010). Hence, studying cultural differences can produce explanations as to how swearwords are used in different cultures.

\section{Method}

\section{Study design and sample}

Incivility research has been typically used a positivist approach (e.g., Scott et al., 2014). However, the interpretivist approach is most suited for understanding human actions, motives, feelings, experiences, and sensemaking (Lucas, 2015). We employed semi-structured interviewing and focused on three groups of highly qualified professionals - lawyers, medical doctors and business executives, because they are not typically considered to be prone to the use of expletive language and are expected to refrain from swearing. In selecting interviewees, we relied on the widely used "key-informant interviews" approach (Gilchrest, 1992) which is not directed at testing hypotheses, but rather at unveiling the state of the art and discovering a sense of reality shared by the population.

Interviews were conducted by the authors and students they had trained in their country of residence (UK, France and the U.S.). We engaged 21 British, 21 French and 10 American professionals; 22 executives, 14 lawyers, 15 medical doctors, 1 army colonel. The sample comprised of 32 men and 20 women, ages ranging from 20 s to $60 \mathrm{~s}$. We stopped recruiting interviewees when the data analysis showed we had reached saturation. Table 1 presents the sample. 
Insert Table 1 about here

Interviewees were asked to provide a narrative account of their experience relating to swearing in organizations. We aimed to hear their "story" (Dyer and Wilkins, 1991). Discussing a sensitive and taboo topic, we took steps to break-the-ice and establish trust. We began with a general question on what their job involved, and then introduced the topic of swearing by recalling well-known recent examples of political leaders using swear words. We then asked whether the interviewee swore at all, at which frequency, in which circumstances, with whom and through which media (face-to-face, phone, email), and which words s/he was using. We inquired about why the interviewee thought it was appropriate, or not, to swear at work, and about their perceived benefits/drawbacks. To alleviate the sensitivity of the topic and to mitigate the risk for social desirability, we asked the same questions regarding others at work. We also gathered demographics and asked whether the interviewee was aware of a company policy around swearing.

In conducting the interviews we were mindful of the intricacies of language utilization (Welch and Piekkari, 2006), and our interviewers were fully conversant in the interviewees' native tongue (English or French). The interview guideline was translated to French using the Brislin (1970) back-translation procedure. The interviews lasted from 30 to 45 minutes. Most of the interviews were tape recorded (with permission) and fully transcribed.

\section{Data analysis}

To analyze the interviews, we used a grounded theory approach (Glaser and Strauss, 1967), offering an alternative to the dominant deductive approach of theory generation (Easterby-Smith et al., 2008). We approached grounded theory from a relativist ontology perspective, which is an approach accepting that reality cannot be fully understood or reconstructed by a researcher since there is no single 'reality' to explore (Corbin and Strauss, 2015). To address issues of interpretation resulting from the diversity of the authors' frameworks for making sense of reality 
(Sandberg, 2005), we fostered reflexivity (Finlay and Gough, 2003) within our research team. We did this by jointly discussing our research questions, the interview questions and protocols to be followed for data collection. When we reached the coding stage, all authors independently engaged in the coding process to ensure inter-rater reliability (Morse, 1997). Moreover, after the first round of coding, the research team discussed data collected in order for all to take into account comments from others in subsequent rounds of analysis.

We (a) analyzed the nature of swearing (words used, frequency, whether it happened when respondents were alone or with co-workers or supervisors) (b) generated codes for reasons for swearing and (c) generated codes for positive and negative outcomes of swearing. We undertook an iterative process (Corbin and Strauss, 2015), to analyze patterns across our sample and within subcategories of our sample. The analysis then moved from a description to interpretation, where we focused on patterns, their meanings and implications in relation to existing literature. Table 2 presents the key themes and associated open codes derived during the data analysis process.

Insert Table 2 about here

\section{Findings}

Swearing occurrence, occupational and gender differences

Almost all interviewees across all countries admitted to swearing. Amongst the most cited incidents triggering swearing were everyday stressors, such as making a mistake, frustrating meetings, and pressure of a nearing deadline,. These stressors caused an emotional release in the form of an immediate expression of feelings through swear words:

"It's more for anger, more for agony, if I am running late, or if someone is definitely upsetting me or if I am having a bad day and someone is constantly on my nerves" (Business executive, Female, UK) 
Our analysis revealed important occupational differences: while business executives tended to swear the most in all three countries, swearing was considered unacceptable in the case of interviewees who held leadership positions where they felt they were expected to lead by example. For instance, a French female doctor explained that a calm and reassuring demeanor was key to creating a climate of safety for patients, and that swearing would be especially unprofessional. In addition, a male U.S. executive discussed how he never swore in front of large groups and only with peers, while a female UK lawyer depicted the taboo as "a gentleman's agreement, that you should not swear when at work."

Swearing taboos also differed per occupation: forbidden situations included specific professional contacts such as patients for doctors, clients for most business executives, as well as specific places or times such as the court for lawyers. For example, a UK male business executive explained that adapting one's language to the audience was considered part of the core management skills.

In our sample, both male and female interviewees admitted to swearing. However, some French female professionals used swearing to assert their identity and earn respect from their male colleagues:

"I swear to be respected as a woman in a job [engineering] and in a company that is rather masculine.” (Business executive, Female, FR)

"I have to show that I can go rough and rude, I don't like it, but it is necessary." (Business executive, Female, FR)

Such affirmative swearing occurred a lot more in male-dominated environments:

“A lot, definitely, especially in a men's environment... when I started work, I was hearing F F F everywhere... All males pretty much use the F word." (Business executive, Female, UK) Interestingly as well, the same female professionals used swear words that are clearly sexual, or target men or women separately, such as "couillon" (turd) for men and "garce" (bitch) for women. They were very aware of gender differences and norms, and were navigating them to their advantage. French men too used sexually connoted words and words targeted to men or 
women only such as "enfoiré" (mother***er), "bordel” (whorehouse) and "putain" (whore). Similarly, in the U.S., a male lawyer discussed how he refers to one female attorney as “c***erella" because he thought she was very "bitchy". One interviewee mentioned how age and social class mattered, implying that managers and professionals might swear less than blue collar workers:

"The younger colleagues tend to swear a lot more. Also, our manual workers tend to swear a lot. ” (Business executive, Male, FR)

\section{Degrees of profanity}

Interviewees made a distinction between "soft swearing" and "hard swearing", for example using "bollocks, or piss" as soft swearing words (Business executive, Male, UK). Some interviewees also distinguished between well-established swear words and the insulting or derogatory language that they admitted to using, despite negative connotations:

"We might use insulting language rather than the common swear words... we may refer to a patient as 'little old lady'." (Doctor, Male, UK)

Further, a distinction was made between swearing and speaking rudely, for example when "Partners [are] rude and shout when stressed, but they don't directly swear at you." (Lawyer, Female, UK). Some words were more taboo than others, particularly in our corporate sample:

"I may say 'the whole situation is completely bollocks' or 'that person should F off'. I don't use the whole F word, I tone it down." (Business executive, Male, UK)

Workplace media through which swearing occurs

Our analysis showed that swearing did not take place in formal meetings, written communications (letters/memos), phone conversations, or emails. Instead, face-to-face swearing between colleagues was the most frequent. Participants discussed how swearing occurred with close colleagues and never with clients (UK female lawyer) or subordinates (U.S., Business executive): 'You can never swear in front of top management, conferences or meetings' 
(Business executive, Female, FR). One French male manager explained that, typically, meeting participants maintain a good level of language during large official meetings and wait until the end of the meeting when they gather in small groups to express their frustration or disagreement in swear words, if they are confident this will not be overheard by management.

\section{Positive outcomes of swearing at work}

Individual benefits. Interviewees felt they gain individual benefits from swearing like recovering from stress and expressing certain emotions (anger, frustration): “It's a mechanism for venting" (Business executive, Male, U.S.). Some of them argued that "people swear without thinking" (Lawyer, Male, UK), it is a way to deal with stress, it helps relieve stress, it airs frustration, sets the basis for responsibility when things go wrong, or breaks a latent conflict. Specific sources of other-related swearing included dangerous situations (e.g., a mentally-ill patient behaving violently), others playing power games (e.g., a doctor arguing with a radiologist who was refusing to examine a patient) and suppliers not reaching quality standards. A UK male executive discussed how swearing was used at work to make a point and to create "cathartic relief" within a very stressful work environment. Similarly, a U.S. male doctor discussed how swearing "might allow for a release of tension, so it might make you feel better" and a make U.S. executive explained that swearing is "used for therapy".

Other interviewees mentioned that they used swearing as a buffering transition ritual to protect their home and family domain from professional tensions. For instance, a French female lawyer explained she swore after speaking in court and that she thought of it as a way to let steam off before being with her children.; in addition, she enjoyed the contrast with the highly polished and technical language.

Furthermore, lawyers and business executives suggested that swearing helped them cope and foster resilience after performing taxing emotional work with a client or a team member. For instance, a UK female sales director compared swearing with smoking a cigarette, she saw it as a 
physiological need after a difficult client negotiation, to express her sadness or her disappointment and move on to the next call:

"It is a really good way of expressing yourself. A good way to release this energy and agony, sometimes it can help a lot, like slamming the doors, the F word can be as helpful and as effective as this." (Business executive, Female, UK)

Interpersonal benefits. Interviewees believed using rough language can get someone's attention or emphasize something. Team leaders in particular said that swearing, because it contrasted with the usual politically correct professional language, conveyed authority, and even a sense of urgency. In short, swearing was a way to get an important job done more quickly. For instance, French business executives use the term "gueuler" (yell) to make one's point to management, in order "to galvanize troops... they understand I am not satisfied" (Business executive, Male, FR). The feeling that "it is necessary to go aggressive to get the work done by others"(Business executive, Male, FR) and that it helped "to motivate others, to make them face what was at stake with the project" (Business executive, Male, FR) was also noted by business executives and lawyers in the UK and U.S.: "When trying to convey a message across" (Business executive, Male, UK); "[I swear] once in a while for effect around here" (Lawyer, Female , U.S.). Likewise, a U.S. male executive said that "rudeness is part of getting the job done”. Similarly, U.S. interviewees mentioned using swearing for humor and to get the other person's attention:

"I call them a perfect rectal aperture... Also known as assholes... It's humorous... It gets their attention..." (Lawyer, Male, U.S.)

"We also swear for effect... The intention is to emphasize humor... It helps lighten the conversation when the people you know are very tolerant of it and you know no one is going to be offended by it." (Business executive, Male, U.S.)

We also found occurrences of swearing used to establish interpersonal relationships. For example, a male UK executive noted that "if me and colleagues swear when discussing 
something, this proves an easiness that we have with one another, a good relationship to the extent of being able to speak to each other like mates do." Similarly, one lawyer stated that swearing introduced fun in the workplace, provided it was well targeted interpersonally:

"It makes working much more fun, you get to know your colleagues. Of course, you simply cannot swear with some other colleagues and definitely not with bosses." (Lawyer, Female, UK).

Likewise, other interviewees saw swearing as a signal that one is comfortable and willing to exchange with coworkers on an informal and more vulnerable basis:

"Sometimes [swearing is used] to better communicate your true feelings about a topic... It can lead to an apology which can actually strengthen a relationship." (Business executive, Male, U.S.)

"If me and colleagues swear when discussing something, this proves an easiness that we have with one another, a good relationship to the extent of being able to speak to each other like mates do." (Business executive, Male, UK)

In particular, it was not unusual to see some employees clarifying their positions after a meeting discreetly in small groups, "some bad words can come out, especially if the meeting has been tense" (Business executive, Female, FR).

On a more controversial note, swearing was sometimes used to affirm status in an aggressive way and to intimidate clients, judges, CEOs or suppliers:

"I have had situations where I have screamed at clients and told them that they were being...assholes... it wakes them up...”(Lawyer, Male, U.S.)

"Swearing helps to break the ice, to be heard, to make others work at your own pace... to intimidate others." (Business executive, Male, FR)

Group benefits. Because swearing was perceived as taboo in the presence of clients or patients, swearing within the group conveyed a sense of belonging, and mutual trust, which was perceived to increase group affiliation, bonding and cohesion: "Part of the way you socialize at 
work” (Lawyer, Female, UK); “a type of joking” (Business executive, Female, UK). Thus, some of our interviewees analyzed other-directed swearing as a group phenomenon indicative of group membership:

"This thing is between the people that spend 8 hours each day in the same office, for the past two and a half years. So it is different, we are like friends." (Business executive, Male, UK)

Evidence of group contagion was present:

“... You have group dynamics. One person swears and all of a sudden everyone in that group swears. It is contagious. "(Lawyer, Female, UK)

Swearing was seen by many interviewees as a way to conform to group norms. For instance, several medical doctors indicated that they considered swearing as a bad professional practice, but still used it to behave in accordance with their organizational culture:

“' $S^{* * *}$ ' sometimes. I might use other swearing words like the 'f word' but only as part of everyday conversations that I am having with colleagues. And only because this is the 'norm', this is how we tell stories between us." (Doctor, Male, UK)

"This is the organizational culture. It is a friendly/swearing environment, our CEO will come up and swear at us, in a joking way." (Business executive, Female, UK)

Group norms and the organizational culture thus reinforced each other and fostered swearing:

"It becomes part of the way you socialize at work." (Lawyer, Female, UK)

"I adapt my language to their language, so if they are very professional and they don't swear then I don't, but if they do and they frequently swear then I match my language to their language." (Business executive, Male, UK)

Reactions to swearing in the workplace

Swearing at work has not backfired for the majority of interviewees. As one respondent commented: 'Swearing is not a crime if people don't take offence' (Lawyer, Female, UK). When 
probed more specifically about their reactions to swearing at the workplace, these depended upon the profession. Doctors mentioned that if some swearing takes place occasionally, they ignore it. However, if there was an individual who was swearing frequently, they would try to address it. Doctors and lawyers stated that swearing is not socially acceptable in their profession and that people would be shocked if it happened as it would show a lack of respect (e.g. towards patients or the court), leadership skills (e.g. doctors leading teams) and control:

"Swearing is not socially acceptable in my workplace... In a legal environment you are sort of expected to always remain calm in any situation and use your logic to resolve issues. It is expected that you will not be in an escalating situation and that you would seek to solve the issue in another way." (Lawyer, Female, UK).

Some business executives seemed to be more accustomed to swearing and tended not to pay particular attention when it is happening. But others acknowledged the negative consequences of swearing. One interviewee mentioned that swearing against superiors is nearly impossible “unless you don't care about keeping your job” (Business executive, Female, FR). French interviewees mentioned that swearing can have negative consequences when it creates conflict, or when it degrades your image and affects the degree to which people want to work with you:

"[swearing] may even hinder me from being promoted or benefit from special treatments. "(Business executive, Female, FR).

In addition, as one manager stated, the extent of swearing at work did in some instances cause problems with customers:

"My role is business development so I am trying to sell the company to the clients. So I am wasting my time when I am saying "we are such a great company, work with us" and then at the background someone is saying F F F, or F this client, or F that client." (Business executive, Female, UK).

Further, swearing was acknowledged as a potential problem in front of religious colleagues. In one case, a male UK doctor discussed how they refrained from using profanity in 
the presence of a religious Christian colleague and how a distressed doctor uttered several words of profanity in front of a sensitive secretary who filed a formal complaint. Similarly, a male U.S. business executive described swearing as "unprofessional... offensive to a third party".

\section{Management's views on swearing at work}

When asked about the top management's views on workplace swearing, the majority of interviewees believed that swearing, although not encouraged, had never been addressed by senior management, nor were they aware of any company swearing policy, although they were aware of policies on equality, diversity, customer service and a general conduct of respect. Lawyers and business executives in the UK and U.S. referred to an understanding that the company expects them to "use common sense" (Business executive, Male, UK) and act "within reason" (Business executive, Male, U.S.). Participants also mentioned that they were aware of unwritten rules of acceptable conduct and professional behavior.

"You learn it and you're taught through feedback. And you develop a sense of what you think is appropriate versus inappropriate but it is not written." (Business executive, Male, U.S.)

\section{Country differences}

Throughout our analysis, we have pointed to differences between our American, French and British samples. While our sample may not allow for generalization, we noted three main differences: (a) gender differences were salient in the discourse of French interviewees, not British or U.S. interviewees; (b) attention to degrees of profanity and subtle differences between swearing and insulting language were found in the UK and U.S. sample, not the French sample; and (c) U.S. interviewees, particularly U.S. lawyers, think of swearing as something less serious and even see the humorous side of it. U.S. interviewees even talked about using swearing to sort out disagreements and further strengthen relationships. Swearing is used for socialization (mainly UK), for making a point or emphasizing something (all) and relieving tension (all). Yet, 
there were many similarities, such as the executives' use of swearing as a motivation tool to make their team aware of the importance and urgency of a specific task or project and get the work done.

\section{Discussion and Conclusion}

Our findings indicate that social swearing (Jay, 2000; Montagu, 2001), although formally unacceptable, does occur at most levels within different organizational contexts and professions. Unlike the assumption that swearing would not occur in high profile occupations (Sliter et al., 2012), we found that it does. This is in stark contrast to the more traditional view that, as a professional, one's duty is to be civil (Fritz, 2013) frequently also due to a fear of losing reputation and authority amongst peers or clients (Andersen, 2009; Miller, 2000).

The most common cited reason for swearing were everyday stressors (Baruch and Jenkins, 2007) which made individuals seek emotional release (Dewe and Gueast, 1990). Swearing was mostly found to occur face-to-face or through informal encounters because of professional language expectations (Johnson and Lewis, 2010), professional norms (Andersen, 2009) and expected behaviors at work (Miller, 2000). Furthermore, our analysis identified both positive and negative outcomes of swearing at work.

At the individual level, swearing was reported as enabling the relief of stress and the expression of emotions such as anger and frustration (Jay and Janschewitz, 2008; Johnson and Indvik, 2001) by creating a cathartic relief for the individual (Dewe and Guest, 1990). Particular reference was made to swearing as a means for coping with emotional work. At the interpersonal level, swearing was used to get attention (Young, 2004), emphasize a point, convey authority (Lindebaum and Fielden, 2011) or a sense of urgency. Interestingly, we found a link between swearing and humor with many participants using swearing in a humorous way to develop friendships at work (Young, 2004), similarly to Montagu's (2001) finding of swearing occurring in interpersonal relationships with the purpose of creating or developing social group membership or in-group solidarity. This finding links with positive outcomes of swearing at the 
group level, such as swearing for creating a sense of belonging, mutual trust, group affiliation, bonding and cohesion, similarly to Baruch's and Jenkin's (2007) social aspects of swearing for group solidarity and cohesion. Taking this a step further, we also found that swearing was also seen as part of the informal organizational culture, although management did not actively encourage this practice. The most prominent negative outcomes were perceptions of lack of respect (Pearson et al., 2001), lack of leadership skills, lack of control, potential to create conflict, and potential to degrade one's image (Stone et al., 2010). We also saw how swearing was used in a purposefully aggressive way to exert power on suppliers and business partners (Moore, 2004).

In terms of gender differences, swearing was reported as beneficial to female professionals who wanted to demonstrate assertiveness in male-dominated environments (Limbrick, 1991). Swearing was used as a resource for identity construction (Stapleton, 2003) to earn respect from their male colleagues.

Our study contributes to three bodies of work. Firstly, we add to the professional/workplace (in)civility theory (e.g. Hadley, 2014; Hershcovis and Reich, 2013; Priesemuth et al., 2013; Scott et al., 2014; Sears and Humiston, 2015; Shao et al., 2011; Soylu and Sheehy-Skeffington, 2015; van Kleef, 2014) by shedding light on the under-researched positive outcomes of swearing. Secondly, we add to the emotional labor literature which predominantly argues for the suppression of negative emotions at work (e.g. Kramer and Hess, 2002; Lively, 2000) by offering to explore the potentially positive aspects of 'negative' behaviors such as swearing at work. As such, we add to the growing body of research studying the potential asymmetrical effects of emotion-sharing in the workplace (e.g. Brown et al., 2005; Gibson and Callister, 2010; Gray et al., 2011; Kennedy-Moore and Watson, 2001; Lindebaum and Fielden, 2011). Thirdly, we add to the literature on social norms for professionals (Andersen, 2009; Miller, 2000; Johnson and Lewis, 2010; Sliter et al., 2012) by arguing against the traditionalist view that workplace incivility should be tackled and eliminated (Jay and 
Janschewitz, 2008; Johnson and Indvik, 2001; Pearson et al., 2000 Rassin and Muris, 2005; Young, 2004).

Our research was limited to three occupations in three countries. Future studies may be conducted in more cultures, covering more cultural clusters, and explore a wider set of professions. We also call for quantitative surveys that measure the positive and negative outcomes of workplace swearing.

Our study has practical implications for business leaders. Our findings imply that although workplace swearing cannot be recommended, or perhaps not even tolerated, many employees have a natural need to swear, either as a stress release mechanism, to emphasize an issue, or to build rapport,. Not every use of bad language represents a hostile work environment and a "zero tolerance" policy might backfire (Geddes and Stickney, 2011). Therefore, it might be relevant for managers to be flexible regarding swearing, by considering what the swearers' intention was and whether the audience may suffer consequences before sanctioning the swearing. Discussing swearing with one's team when it occurs too frequently or may be hurtful may be an avenue to consider. Last, advice should be given to everyone in the workplace on the need to think before you speak.

In conclusion, we hope that this study can help to nuance scholars', practitioners' and policy makers' understanding of swearing at the workplace. 


\section{References}

Andersen, L. B. (2009), "What determines the behavior and performance of health professionals? Public service motivation, professional norms and/or economic incentives", International Review of Administrative Sciences, Vol. 75, No. 1, pp. 79-97.

Baruch, Y. and Jenkins, S. (2007), "Swearing at work and permissive leadership culture: When anti-social becomes social and incivility is acceptable", Leadership and Organization Development Journal, Vol. 28, No. 6, pp. 492-507.

Baruch, Y. \& Vardi, Y. (2016), “A fresh look at the dark side of contemporary careers: Toward a realistic discourse”, British Journal of Management, Vol. 27, No. 2, pp. 355-372.

Brislin, R.W. (1970), “Back-translation for cross-cultural research”, Journal of Cross-Cultural Psychology, Vol.1, No. 3, pp. 185-216.

Brown, S. P., Westbrook, R. A. and Challagalla, G. (2005). “Good cope, bad cope: Adaptive and maladaptive coping strategies following a critical negative work event", Journal of Applied Psychology, Vol. 90, No. 4, pp. 792-798.

Corbin, J. and Strauss, A. (2015), Basics of Qualitative Research: Techniques and Procedures for Developing Grounded Theory ( $4^{\text {th }}$ ed.), SAGE, Thousand Oaks.

Corley, K. G. (2015), “A commentary on 'what grounded theory is...': Engaging a phenomenon from the perspective of those living it”, Organizational Research Methods, Vol. 18, No. 4, pp. 600-605.

Coupland, C., Brown, A. D., Daniels, K. and Humphreys, M. (2008), "Saying it with feeling: Analysing speakable emotions", Human Relations, Vol. 61, No. 3, pp. 327-353.

Dewe, P.J. and Guest, D.E. (1990), "Methods of coping with stress at work: A conceptual analysis and empirical study of measurement models", Journal of Organizational Behavior, Vol. 11, No. 2, pp. 135-150.

Diefendorff, J. M. and Greguras, G. J. (2009), "Methods of coping with stress at work: Examining the roles of targets and discrete emotions in shaping display rule perceptions", Journal of Management, Vol. 35, No. 4, pp. 880-898. 
Dyer, W. and Wilkins, A. (1991), "Better stories, not better constructs, to generate better theory: a rejoinder to Eisenhardt", Academy of Management Review, Vol. 16, pp. 613-619.

Easterby-Smith, M., Golden-Biddle, K. and Locke, K. (2008), "Working with pluralism: Determining quality in qualitative research”, Organizational Research Methods, Vol. 11, pp. $419-429$.

Finlay, L. and Gough, B. (2003), Reflexivity: A Practical Guide for Researchers in Health and Social Sciences, Blackwell Science, Oxford.

Fritz, J. M. H. (2013), Professional Civility: Communicative Virtue at Work, Peter Lang, New York.

Geddes, D. and Stickney, L.T. (2011), “The trouble with sanctions: Organizational responses to deviant anger displays at work", Human Relations, Vol. 64, pp. 201-230.

Gibson, D. E. and Callister, R. R. (2010), “Anger in organizations: Review and integration”, Journal of Management, Vol. 36, pp. 66-93.

Gilchrest, V.J. (1992), “Key informant interviews”, Crabtree, B.F. and Miller, W.L. (Eds.), Doing Qualitative Research, SAGE, London, pp.71-88.

Gray, H. M., Ishii, K. and Ambady, N. (2011), "Misery loves company: When sadness increases the desire for social connectedness", Personality and Social Psychology Bulletin, Vol. 37, pp. $1438-1448$.

Gross, J. J. (1999), Emotion and emotion regulation. In L. Pervin and P. P. John (Eds.), Handbook of Personality: Theory and Research (2 ${ }^{\text {nd }}$ ed.), Guildford, New York, pp. 525552.

Hadley, C. N. (2014), "Emotional roulette? Symmetrical and asymmetrical emotion regulation outcomes from coworker interactions about positive and negative work events", Human Relations, Vol. 67, pp. 1073-1094.

Hershcovis, M.S. and Reich, T.C. (2013), "Integrating workplace aggression research: Relationship, contextual, and method considerations", Journal of Organizational Behavior, Vol. 34, pp. S27-S42. 
Jay, T. (2000), Why we Curse: A Neuro-psycho-social Theory of Speech, John Benjamins Publishing Co., Amsterdam.

Jay, T. and Janschewitz, K. (2008), "The pragmatics of swearing”, Journal of Politeness Research, Vol. 4, pp. 267-288.

Johnson, P.R. and Indvik, J. (2001), “Slings and arrows of rudeness: Incivility in the workplace", Journal of Management Development, Vol. 20, pp. 705-714.

Johnson, D.I. and Lewis, N. (2010), “Perceptions of swearing in the work setting: An expectancy violations theory perspective", Communication Reports, Vol. 23, pp. 106-118.

Kaye, B.K. and Sapolsky, B.S. (2009), "Taboo or not taboo? That is the question: Offensive language on prime-time broadcast and cable programming”, Journal of Broadcasting and Electronic Media, Vol. 53, pp. 22-37.

Kennedy-Moore, E. and Watson, J.C. (2001), “How and when does emotional expression help?”, Review of General Psychology, Vol. 5, pp. 187-212.

Kramer, M. W. and Hess, J. A. (2002), "Communication rules for the display of emotions in organizational settings", Management Communication Quarterly, Vol. 16, pp. 66-80.

Lim, S., and Lee, A. (2011),” Work and nonwork outcomes of workplace incivility: Does family support help?", Journal of Occupational Health Psychology, Vol. 16, pp. 95-111.

Limbrick, P. (1991), “A study of male and female expletive use in single and mixed sexsituations", Te Reo: The Journal of the Linguistic Society of New Zealand, Vol. 34, pp. 71-89.

Lindebaum, D. and Fielden, S.L. (2011), "It's good to be angry: Enacting anger in construction project management to achieve perceived leader effectiveness", Human Relations, Vol. 64, pp. $437-458$.

Lively, K. J. (2000), "Reciprocal emotion management: Working together to maintain stratification in private law firms", Work and Occupations, Vol. 27, pp. 32-63. 
Miller, G. J. (2000), “Above politics: Credible commitment and efficiency in the design of public agencies”, Journal of Public Administration Research and Theory, Vol. 10, pp. 289328.

Montagu, A. (2001), The Anatomy of Swearing. University of Pennsylvania Press, Pennsylvania.

Moore, R. L. (2004), “We're cool, mom and dad are swell: Basic slang and generational shifts in values”, American Speech, Vol. 79, pp. 59-86.

Morse, J.M. (1997). Editorial - Perfectly health, but dead: The myth of inter-rater reliability. Qualitative Health Research, 7(4), 445-447. doi: 10.1177/104973239700700401

Pearson, C.M., Andersson, L.M. and Wegner, J.W. (2001), "When workers flout convention: A study of workplace incivility”, Human Relations, Vol. 54, pp. 1387-1419.

Pearson, C.M., Anderson, L.M. and Porath, C.L. (2000), “Assessing and attacking workplace incivility”, Organizational Dynamics, Vol. 29, No. 2. pp. 123-137.

Penney, L. M. and Spector, P. E. (2005), “Job stress, incivility, and counterproductive work behavior (CWB): The moderating role of negative affectivity", Journal of Organizational Behavior, Vol. 26, pp. 777-796.

Priesemuth, M., Arnaud, A. and Schminke, M. (2013), "Bad behavior in groups: The impact of overall justice climate and functional dependence on counterproductive work behavior in work units", Group \& Organization Management, Vol. 38, pp. 230-257.

Rassin, E. and Muris, P. (2005), "Why do women swear? An exploration of reasons for and perceived efficacy of swearing in Dutch female students", Personality and Individual Differences, Vol. 38, pp. 1669-1674.

Rassin, E. and van der Heijden, S. (2005), “Appearing credible? Swearing helps!”, Psychology, Crime \& Law, Vol. 11, pp. 177-182.

Sandberg, J. (2005), "How do we justify knowledge produced within interpretive approaches?", Organizational Research Methods, Vol. 8, pp. 41-68. 
Schilpzand, P., De Pater, I.E. and Erez, A. (2016), "Workplace incivility: A review of the literature and agenda for future research”, Journal of Organizational Behavior, Vol. 37, pp. S57-S88.

Scott, K.L., Zagenczyk, T.J., Schippers, M., Purvis, R.L. and Cruz, K.S. (2014), “Co-worker exclusion and employee outcomes: An investigation of the moderating roles of perceived organizational and social support”, Journal of Management Studies, Vol. 51, pp. 12351256.

Sears, K., and Humiston, G. S. (2015), “The role of emotion in workplace incivility”, Journal of Managerial Psychology, Vol. 30, No. 4, pp. 390-405.

Shao, P., Resick, C.J. and Hargis, M.B. (2011), "Helping and harming others in the workplace: The roles of personal values and abusive supervision”, Human Relations, Vol. 64, pp. 1051-1078.

Sliter, M., Sliter, K., and Jex, S. (2012), "The employee as a punching bag: The effect of multiple sources of incivility on employee withdrawal behavior and sales performance", Journal of Organizational Behavior, Vol. 33, No. 1, pp. 121-139.

Soylu, S. and Sheehy-Skeffington, J. (2015), “Asymmetric intergroup bullying: The enactment and maintenance of societal inequality at work", Human Relations, Vol. 68, pp. 10991129.

Stapleton, K. (2003), "Gender and swearing: A community practice”, Women and Language, Vol. 26, pp. 22-33.

Stephens, R. and Umland, C. (2011), "Swearing as a response to pain: Effect of daily swearing frequency", The Journal of Pain, Vol. 12, pp. 1274-1281.

Stone, T.E., McMillan, M. and Hazelton, M. (2010), "Swearing: Its prevalence in healthcare settings and impact on nursing practice", Journal of Psychiatric and Mental Health Nursing, Vol. 17, No. 6, pp. 528-534. 
Stone, T. and Francis, L. (2010), "What's the bloody law on this? Nurses, swearing, and the law in New South Wales, Australia", Advances in Contemporary Mental Health Nursing, Vol. 34, No. 2, pp. 248-257.

Sypher, B.D. (2004), "Reclaiming civil discourse in the workplace", Southern Communication Journal, Vol. 69, No. 3, pp. 257-269.

Van Kleef, G.A. (2014), "Understanding the positive and negative effects of emotional expressions in organizations: EASI does it”, Human Relations, Vol. 67, No. 9, pp. 11451164.

Van Lancker, D.V. and Cummings, J.L. (1999), "Expletives: Neurolinguistic and neurobehavioral perspectives on swearing”, Brain Research Reviews, Vol. 31, No. 1, pp. 83-104.

Vardi, Y. and Weitz, E. (2004), Misbehavior in Organizations: Theory, Research, and Management, Lawrence Erlbaum Associates, London, NJ.

Welbourne, J. L., Gangadharan, A., and Esparza, C. A. (2016), “Coping style and gender effects on attitudinal responses to incivility", Journal of Managerial Psychology, Vol. 31, No. 3, pp. $720-238$.

Welch, C. and Piekkari, R. (2006), “Crossing language boundaries: Qualitative interviewing in international business”,. Management International Review, Vol. 46, No. 4, pp. 417-437.

White, R. (2002), “Indigenous young Australians, criminal justice and offensive language”, Journal of Youth Studies, Vol. 5, No. 1, pp. 21-34.

Young, S.L. (2004), "What the __ is your problem? Attribution theory and perceived reasons for profanity usage during conflict”, Communication Research Reports, Vol. 21, No. 4, pp. 338-347. 
Table 1

\section{Description of the sample}

\begin{tabular}{|c|c|c|c|}
\hline & UK & FR & U.S. \\
\hline Lawyers & $\begin{array}{l}7 \text { (4 male, } 3 \text { female) } \\
\text { Senior Partner, M, } 49 \\
\text { Partner, M, 39 } \\
\text { Solicitor, M, } 27 \\
\text { Solicitor, M, } 35 \\
\text { Partner, F, 43 } \\
\text { Solicitor, F, 34 } \\
\text { Solicitor, F, 32 }\end{array}$ & $\begin{array}{l}3 \text { (female) } \\
\text { Lawyer, F, } 42 \\
\text { Lawyer, F, } 44 \\
\text { Lawyer, F, } 48\end{array}$ & $\begin{array}{l}4 \text { ( } 2 \text { male, } 2 \text { female) } \\
\text { Senior Attorney, M, 50-59 } \\
\text { Owner/Attorney, M, 50-59 } \\
\text { Divorce Lawyer, F, 30-39 } \\
\text { Attorney, F, age undisclosed }\end{array}$ \\
\hline $\begin{array}{l}\text { Medical } \\
\text { doctors }\end{array}$ & $\begin{array}{l}7 \text { (3 male, } 4 \text { female) } \\
\text { Endocrinologist, M, } 62 \\
\text { Gastroenterologist, M, } 48 \\
\text { Anesthesiologist, M, } 45 \\
\\
\text { General Practitioner, F, } 52 \\
\text { General practitioner, F, } 58 \\
\text { Dentist, F, 53 } \\
\text { Emergency Doctor, F, } 56\end{array}$ & $\begin{array}{l}6 \text { (3 male, } 3 \text { female) } \\
\\
\text { Hospital Intern, M, } 27 \\
\text { Dietician, M, 28 } \\
\text { Psychiatrist, M, } 33 \\
\\
\text { Medical Social Worker, F, } 26 \\
\text { Autism Specialist, F, } 33 \\
\text { Psychiatrist \& Head of } \\
\text { Department, F, } 47\end{array}$ & $\begin{array}{l}2 \text { (male) } \\
\text { Physician, M, 50-59 } \\
\text { Colo-rectal Surgeon, M, 60- } \\
69\end{array}$ \\
\hline $\begin{array}{l}\text { Business } \\
\text { executives }\end{array}$ & $\begin{array}{l}7 \text { (6 male, } 1 \text { female) } \\
\text { HR Business Partner, M, } 31 \\
\text { Marketing Manager, M, } 32 \\
\text { Business Development } \\
\text { Manager, M, 34 } \\
\text { HR Manager, M, } 38 \\
\text { E-Marketing Manager, M, } 40 \\
\text { General Manager, M, 57 } \\
\text { Business support consultant, } \\
\text { F, 20-29 }\end{array}$ & $\begin{array}{l}11 \text { (7 male, } 4 \text { female) } \\
\text { Project Leader, M, } 30 \\
\text { Project Leader, M, } 31 \\
\text { Industrial Product Manager, } \\
\text { M, 31 } \\
\text { Industrial Director, M, } 33 \\
\text { IT Manager, M, 33 } \\
\text { IT Manager, M, 33 } \\
\text { Asset Manager, M, } 34 \\
\text { Accounting Manager, F, } 24 \\
\text { Communications Engineer, F, } \\
25 \\
\text { Brand Manager, F, } 27 \\
\text { Event Manager, F, } 33\end{array}$ & $\begin{array}{l}4 \text { (male) } \\
\text { President/Principle, M, 50-59 } \\
\text { Branch Manager, M, 50-59 } \\
\text { CEO, M, 50-59 } \\
\text { Senior Director, M, 50-59 }\end{array}$ \\
\hline Other & & 1 Army Colonel, M, 50 & \\
\hline Total & 21 interviews & 21 interviews & 10 interviews \\
\hline
\end{tabular}


Table 2: Key themes and associated open codes derived during the data analysis process

\section{$\begin{array}{ll}\text { Core themes } & \text { Open codes }\end{array}$}

1. Nature

2. Causes

3. Attitudes

4. Workplace media

5. Positive outcomes

6. Negative outcomes

7. Management views "swear words", "derogatory language", "soft swearing", "frequency", "degree"

"stress", "after making mistake", "meetings", "pressure of deadline", "pressure of interacting with patients (doctors)", "don't like colleagues", "frustration", "disagreement", "anger"

"unacceptable", "unprofessional", "taboos", "management skills", "respect (women)", "gendered swear words", "workgroup culture", "social class", "leadership"

"formal meetings", "written communications", "phone conversations", "informal emails", "face-to-face"

"stress relief", "express anger", "express frustration", "break conflict", "assign responsibility", "power", "manage suppliers", "spillover of professional tensions to family domain", "coping mechanism", "draw attention", "emphasis", "authority", "sense of urgency", "humor", "motivation", "build rapport", "make a point", "effective communication", "disempower person", "build trust", "group affiliation/belonging", "group bonding", "group cohesion"

"reactions from colleagues", "lack of respect", "unprofessional", "not accepted by management", "impact on customer relations"

"accepted", "not accepted", "policies", "un-written rules" 